\title{
Call for Papers: Special Issue of Earth, Planets and Space (EPS)
}

We now invite papers to a special issue of EPS entitled "Geohazards and the Role of Space-Borne Observations." This special issue will be based on, but not limited to, the papers which will be presented at the ISRS 2006 PORSEC meeting (http://www.isrs2006porsec.com), special session "Geohazards and the Role of Satellite Observations", to be held in Busan, Korea, during 7-10 November 2006. Papers not presented at the meeting but addressing the themes of the Special Issue are also welcome. Suitable subjects include, but are not limited to, observing, modeling and mitigating geohazards associated with earthquakes, volcanoes, ground subsidence, tsunamis, sea level rise, storm surges from typhoon and hurricanes, and meteorite impacts.

Contributors to this special issue should submit their papers directly to the EPS editorial office either by post or by e-mail (eps@terrapub.co.jp), following the instructions for regular EPS submission. For details, please visit the following web page:

http://www.terrapub.co.jp/journals/EPS and click on "Information for Contributors."

Please state "For Special Issue for Geohazards and the Role of Space-Borne Observations" clearly in the cover letter when submitting. We encourage electronic submissions. The submitted papers will be peer reviewed as are all EPS regular papers. After papers are accepted, the authors will receive instructions for the final manuscript from the editorial office.

The deadline for manuscript submissions for this special issue is August 31, 2006. We expect the special issue to be published in February 2007.

For more information on this special issue, please contact the corresponding editor (Prof. J. W. Kim: jwkim@sejong.ac.kr) while questions on manuscript preparation should be addressed to the EPS editorial office.

Guest Editors: J. W. Kim, jwkim@sejong.ac.kr

C. K.Shum, ckshum@osu.edu

B. F.Chao, chao@bowie.gsfc.nasa.gov 